\title{
INVASÃO OU OCUPAÇÃO? A ESTRATÉGIA ARGUMENTATIVA DO PODER JUDICIÁRIO NAS DECISÕES ENVOLVENDO O INGRESSO EM IMÓVEIS ABANDONADOS
}

\section{SQUATTING OR INVASION OF PRIVATE LAND OR PROPERTY? THE ARGUMENTATIVE STRATEGY OF JUDICIAL POWER ON DECISIONS INVOLVING OCCUPYING LAND WITHOUT LEGAL CLAIM}

\section{Alexandre de Castro Coura ${ }^{1}$ \\ Renata Helena Paganoto Moura²}

\section{RESUMO}

O presente artigo busca compreender como, num sistema de regras explícitas, há tantas decisões contraditórias, sobre o mesmo fato. A dialética se apresenta como método de abordagem de decisões acerca de ocupação de imóveis abandonados selecionadas por meio de amostra nãoprobabilística intencional. Como ponto de partida do viés dialético, utiliza-se a distinção entre o senso comum teórico dos juristas e o saber crítico proposto por Warat, além de sua crítica à epistemologia dos conceitos e a análise realizada por Katharina Sobota do silogismo, enquanto estilo de apresentação da decisão judicial. Como resultado, tem-se que o senso comum teórico dos juristas esconde o jogo estratégico do discurso; a decisão é construída para dar uma sensação de completude e coerência lógica, deixando de revelar que o que move a interpretação dessas ações ora é a defesa intransigente de uma propriedade liberal, em que o proprietário é o senhor absoluto dos poderes que Ihe são atribuídos por lei; ora é a defesa da função social, mas, apesar de muitos avanços, o terreno político atual corrobora para manutenção da primeira. Assim, em ações judiciais acerca do ingresso em imóveis, não há um consenso no processo decisório: ora a propriedade abandonada "autoriza" o ingresso para moradia, ora "não autoriza". Ora são invasores, ora são ocupantes.

Palavras-chave: Ocupação. Invasão. Propriedade. Propriedade abandonada. Função social da propriedade.

\footnotetext{
1 Pós-doutorado como visiting scholar na American University e visiting foreign judicial fellow no Centro Judiciário Federal em Washington D.C. Doutor e Mestre em Direito Constitucional pela Universidade Federal de Minas Gerais (UFMG). Ex-professor efetivo de Direito material e processual penal da Universidade Federal do Espírito Santo (UFES). Professor de Teoria dos Direitos Fundamentais no Programa de Mestrado e Doutorado da Faculdade de Direito de Vitória (FDV). Promotor de Justiça Cível da Comarca da Serra/ES (Patrimônio público e defesa dos consumidores). Afiliação: Faculdade de Direito de Vitória (FDV) Lattes: http://lattes.cnpq.br/5164681013190401. ORCID: https://orcid.org/0000-0001-7712-3306 E-mail: acastrocoura @gmail.com

2 Doutoranda em Direito pela Faculdade de Direito de Vitória. Mestre em Processo Civil pela Pontifícia Universidade Católica de São Paulo. Professora de Direito Civil da Faculdade de Direito de Vitória (FDV). Advogada. Afiliação: Faculdade de Direito de Vitória (FDV) Lattes: http://lattes.cnpq.br/6826515973212722. ORCID: https://orcid.org/0000-0003-0676-1487 E-mail:renata@mediacaoeadvocacia.com.br
} 


\section{ABSTRACT}

The objective of this paper was to fathom how many contradictory decisions about the outcome of the same case are reached in a system of explicit rules. The dialectic method was used to approach decisions previously selected by Purposive non-probability sampling concerning squatting of abandoned properties. As a starting point for the dialectic bias, this study used the dissimilarity between the theoretical common sense of legal experts and the critical knowledge by Warat, along with his critique of the epistemology of concepts and the analysis of the syllogism by Katharina Sobota as presentation style of the court decision. As a result, it was concluded that the theoretical common sense of legal experts disguises strategies of speech. The decision is developed so as to convey a sense of comprehensiveness and logical coherence, failing to disclose that what actually fuels the interpretation of these actions is either the inflexible defense of a liberal property in which the owner is the absolute master of the power legally assigned to him or the defense of the social function of the estate. Despite many advances, the current political arena supports the upkeep of the former. Thus, there is no consensus in the decision-making process of lawsuits about squatting private property: the abandoned estate either "allows entrance" or "does not allow it". The trespassers are either squatters or occupants.

Keywords: Squatting. Invasion. Estate. Abandoned property. Social function of the property.

\section{INTRODUÇÃO}

O judiciário tem enfrentado cotidianamente ações de reintegração de posse em imóveis abandonados, ou cujo abandono é o mote principal da ação. Esse tipo de ação não é algo recente e, mesmo em tempos de pandemia, muitas ações continuaram a ser dirigidas ao judiciário, buscando a reintegração de posse de imóveis que são designados como - ora ocupados, ora invadidos. Essa dicotomia entre invasão e ocupação revela muito mais do que pode parecer.

Este artigo busca compreender como, num sistema de regras explícitas, há tantas decisões contraditórias sobre o ingresso em imóveis abandonados, e como a elaboração das expressões invasão $X$ ocupação e imóvel vazio $X$ imóvel abandonado, para o mesmo fato jurídico, demonstram que, para além de uma conclusão lógica, há um exercício discursivo para transformar racionalmente a decisão. Até a propriedade pública e privada ganha distinções que não se encontram no texto da lei, mas que reforçam seu sentido político. 
Deste modo, este trabalho analisa, na primeira parte, a pretensão da verdade ou o mito da cientificidade do direito e como esta elaboração contribui para um modelo de decisão que encobre suas contradições; já, no segundo capítulo, demonstra-se, por meio da análise de decisões judiciais, como estas são construídas para dar uma sensação de completude e coerência lógica. Assim, o que é a propriedade, como é garantida e a quem deve ser protegida é o que muitas vezes, não se explicita nesse discurso jurídico.

Apenas para esclarecer, como este estudo não pretende ser uma análise exaustiva de decisões que envolvem tal temática, recorreu-se ao procedimento de amostragem, visto que ela "é uma parte essencial do procedimento científico" (BARROS; LEHFELD, 2005, p.57). Deste modo, neste estudo, empregou-se a amostragem não-probabilística, pois, neste caso, "a chance de cada elemento da população ser incluído na amostra é desconhecida" (MOURA; FERREIRA; PAINE, 1998, p. 59). Por este estudo estar pautado em uma natureza dialética, empregou-se, portanto, a amostra nãoprobabilística intencional que ocorre nos casos em que, "na opinião do pesquisador, tem, a priori, as características específicas que ele deseja ver refletida na sua amostra" (MOURA; FERREIRA; PAINE, 1998, p. 60).

Assim, as decisões a serem analisadas serão designadas de D1, D2, D3, D4, D5, D6 para manter uma uniformidade de tratamento dos dados ao longo deste trabalho. Deste modo, segue uma tabela em que constará o número do processo, o tribunal e a designação a ser utilizada no texto.

\begin{tabular}{|c|c|c|}
\hline DESIGNAÇÃO & NÚMERO DO PROCESSO & TRIBUNAL|JUIZ OU RELATOR \\
\hline D1 & Apelação Cível no 13217451 & $\begin{array}{l}\text { TJ/PR. Relator: Fernando Paulino da } \\
\text { Silva Wolff Filho }\end{array}$ \\
\hline D2 & $\begin{array}{l}\text { Recurso inominado no Juizado Especial no } \\
20040510087275\end{array}$ & TJ/DF. Relator: Juiz João Batista Teixeira \\
\hline D3 & $\begin{array}{l}\text { Ação de Reintegração de Posse no } \\
\text { 0045635-59.2011.8.26.0053 }\end{array}$ & $\begin{array}{l}\text { TJ/SP. Juiz Luís Fernando Camargo de } \\
\text { Barros Vidal }\end{array}$ \\
\hline D4 & $\begin{array}{l}\text { Agravo de Instrumento } \mathrm{n} \text { - } \\
223532851.2015 .8 .26 .0000\end{array}$ & TJ/SP. Relator: Juiz Álvaro Torres Junior \\
\hline D5 & Apelação Cível no 1007824.78.2015.8.26.0127 & TJ/SP. Relator Spoladore Dominguez \\
\hline D6 & $\begin{array}{l}\text { Recurso Especial no } 1.296 .964 \text { - DF } \\
(2011 / 0292082-2)\end{array}$ & $\begin{array}{l}\text { STJ. Relator Ministro Luís Felipe } \\
\text { Salomão }\end{array}$ \\
\hline
\end{tabular}




\section{UM BREVE PANORAMA ACERCA DAS DECISÕES JUDICIAIS EM AÇÕES DE REINTEGRAÇÃO DE POSSE SOBRE IMÓVEIS ABANDONADOS}

Há uma disputa ocorrendo na cidade segregada, a disputa por seus lugares e um destes são os imóveis abandonados. Essa disputa ocorre no plano fático, com suas ocupações e invasões e no plano jurídico com o sentido legal da propriedade abandonada que implicará em decisões ora protegendo essa propriedade, ora 'despejando' seus invasores.

Em 2009, por exemplo, o Tribunal de Justiça de Minas Gerais (TJ/MG) na Apelação Cível no 100240586459530011, determinou a reintegração de posse de imóvel que a despeito do reconhecido descumprimento da função social da propriedade foi invadido pelo Movimento dos Sem Terra (MST).

Mas, em 2012, a 3a Vara da Fazenda Pública de São Paulo na Ação de reintegração de posse no 0045635-59.2011.8.26.0053 não concedeu a reintegração de posse requerida pelo Município, apesar do esbulho realizado pela Frente por Luta por Moradia, pois entendeu haver uma colisão de direitos entre propriedade e moradia, entendendo que a moradia nesse caso, deveria ser protegida.

Já em 2017, a Justiça Federal da 2a Região na Ação de reintegração de posse № 001260097.2017.4.02.5001, manteve os ocupantes de um imóvel, considerando que o abandono do prédio há anos e a ausência de previsão de utilização justificavam a manutenção dos possuidores no bem localizado no centro de Vitória-ES.

Em 10 de maio de 2020, o TJ/SP no julgamento da Apelação Cível n. 106996430.2018.8.26.0100, determinou que os invasores fossem retirados do imóvel, extraindo-se o seguinte trecho do voto

ainda que hipoteticamente se admitisse o descumprimento da função social da propriedade, tal fato não autorizaria a autotutela por parte dos réus, uma vez que muitas outras pessoas, talvez até mais necessitadas, carecem de moradia e estariam sendo alijadas de tal direito pela mera atuação célere dos invasores, sendo que o dever de garantir tais direitos conforme sua necessidade incumbe ao Estado e não ao indivíduo "motu próprio".

Em 02 de março de 2016, no julgamento da Ação Civil Pública no 000028877.2014.8.26.0447, a 13a Câmara de Direito Público do TJ/SP, considerou que, apesar de ser irrelevante a boa-fé dos ocupantes sobre bem público, pois este não induz posse a favor de particular, que sobre ele exerce mera detenção, e que o Direito fundamental à moradia não autoriza a invasão de bem público, porém pela utilização dos critérios de proporcionalidade e ponderação, na colisão entre direitos fundamentais, é dever da Municipalidade a realocação das famílias para desocupação da área pública. 
Mas em 06 de maio de 2020, mesmo existindo o cenário de pandemia, isso não impediu que o imóvel invadido por um grupo de famílias fosse reintegrado a despeito de toda alegação de risco de contágio e do contrassenso à própria medida governamental de "ficar em casa". ${ }^{3}$

Dessas decisões e das ações que foram ajuizadas ficam implícitas algumas perguntas: afinal as pessoas invadiram ou ocuparam o bem? O imóvel estava vazio ou abandonado? 0 descumprimento da função social da propriedade autoriza o ingresso na propriedade? $\mathrm{O}$ direito de propriedade garante o não-uso da propriedade? $E$, por fim, será que há diferença entre a propriedade pública e a propriedade privada no que toca ao abandono da propriedade?

Os autores de todas as ações descritas alegaram que o imóvel foi invadido - houve um esbulho e daí o direito de pleitear a reintegração de posse, mas os réus alegaram que não esbulharam, apenas ocuparam o bem que estava abandonado, logo não houve, de fato, esbulho, por isso não caberia a reintegração de posse. Apenas para ficar nesse momento no embate entre o esbulho e ocupação.

Mas afinal o que a norma diz? Num sistema legal com abundância de normas como o nosso, herdeiro de um positivismo que crê na completude do ordenamento e em seu sistema lógico (pirâmide), há uma crença de que o direito é constituído de normas explícitas. (SOBOTA, 1996).

Afinal, sabendo-se qual é a norma, bastará deduzir de sua premissa maior, incluindo a premissa menor, pôr fim à conclusão.

Mas qual seria a premissa maior nesses casos? Perde-se a propriedade por abandono (premissa maior); João ingressou em uma propriedade abandonada (premissa menor); logo João ocupou a propriedade, e não sendo a ocupação um ato ilícito, deve manter-se no bem (conclusão).

Mas e quando o ato é considerado ilícito? - Perde-se a propriedade por abandono (premissa maior); João ingressou em propriedade que não estava abandonada (premissa menor), logo o ingresso de João foi ilícito e sendo um esbulho deve sair do bem (conclusão)?

\footnotetext{
${ }^{3}$ Refere-se ao processo no 1001115-49.2020.8.26.0451 da 4a Vara Cível da Comarca de Piracicaba. Em decisão apreciando o pedido de reconsideração, tendo em vista o estado de emergência sanitária, a juíza manteve a liminar de reintegração, alegando em trecho da sua decisão que "Por fim, é certo que a situação de pandemia não impede, por si, o cumprimento de atos de natureza urgente, como no presente caso, mormente diante das informações constantes nos autos de que o número de famílias que se encontram no local é diminuto. Ao revés, postergar o cumprimento da ordem para data indeterminada permitirá a continuidade da movimentação constante existente no local para demarcação irregular de lotes e construções de barracos, além de possibilitar que outras famílias fixem moradia no local, o que contribuirá efetivamente para a propagação da contaminação pelo coronavírus.". O caso teve muita repercussão nas mídias, sendo, inclusive alvo de uma matéria na Carta Capital: FERREIRA, Allan Ramalho. O estado veste o traje da morte: a reintegração de posse e a pandemia. A negação de direitos é a faceta mais visível do processo de criminalização da população sem-teto e sem-terra no Brasil. (Carta Capital, São Paulo, 11/06/2020. Disponível em: https://www.cartacapital.com.br/blogs/br-cidades/o-estado-veste-o-traje-da-morte-a-reintegracao-de-possee-a-pandemia/. Acesso em 27 jun. 2021)
} 
E quando a propriedade for pública, como devemos compreender o ingresso diante do abandono? - Não há posse sobre bem público (premissa maior); João ingressou em propriedade pública que estava abandonada (premissa menor), logo, não sendo possuidor João deve sair (conclusão)?

O que talvez não se perceba tão claramente é que a utilização desse aparente silogismo, é uma estratégia desse jogo discursivo, na utilização dessa norma. Há uma elaboração implícita da premissa maior, crendo assim que tudo não passa de uma simples conclusão.

O silogismo, como afirma Sobota (1996, p. 254), não é um método de decisão, mas um estilo de apresentação da decisão legal, que constrói essa ilusão de certeza.

Omite-se a estratégia discursiva ou retórica, tudo parece uma construção lógica e coerente e a moral também surge para reforçar esse aparente argumento legal, afinal, de um lado, invadir é algo criminoso, remete-nos à ideia de violência, que deve ser repelida e afastada. Assim como abandono é algo desidioso, revela uma falta, que não pode ser tolerada'.

Mas não se reconhece, como aponta Warat (1982, p. 49), o sentido político da normatividade, por meio de um discurso científico que os juristas elaboram em nome da verdade, a epistemologia jurídica oficial, esconde as verdades jurídicas, pois estas exigem a explicitação das relações de força, que formam domínios de conhecimento e sujeitos como efeitos do poder e do próprio conhecimento.

\section{A ESTRATÉGIA DO DISCURSO JURÍDICO E SUA PRETENSÃO DE VERDADE NA CONSTRUÇÃO DOS CONCEITOS DE INVASÃO E DE OCUPAÇÃO DA PROPRIEDADE IMÓVEL}

Warat (1982, p. 50) afirma que "a ortodoxia epistemológica reduz as significações a conceitos, trata-se, segundo o autor, de uma demarche conceitual, que procura colocar, fora de dúvida e fora da política, a fala da ciência".

A busca por um caráter científico do direito exigiu uma construção que the desse neutralidade axiológica, completude sistemática, exatidão na linguagem e na interpretação dos fatos e das normas.

O positivismo jurídico ainda goza, em nossa tradição, de grande prestígio. É fato que qualquer advogado, qualquer estudante de direito, qualquer profissional ainda lê "positivismo" enquanto ciência normativa do direito. No entanto, pincipalmente a partir da traumática experiência do pós-Segunda Guerra, começou a se fazer necessária uma reformulação geral de algumas dessas bases do positivismo, já que as situações do mundo fático não podem ser todas antecipadas pela lei e tratadas a partir de regras objetivas aplicáveis por mera subsunção. Além disso, a ênfase dada a uma 
dimensão principiológica, marcada pela clara intromissão de elementos ligados às noções predominantes de justiça e de moral coloca em definitivo xeque a clássica versão do positivismo jurídico.

Por isso, o positivismo jurídico é posto sob suspeição e imprime, por vezes, uma imagem negativa naquele que o defende. A partir de certo ponto, ser positivista é ser um pensador acrítico, sem preocupações sociais e morais. O positivismo é a ciência da lei, justa ou injusta, cabendo ao aplicador simplesmente aplicá-la. Isso se deve, em grande medida, às grandes críticas sofridas por esse sistema no Direito, principalmente, por ter sido apontado como o responsável pela legitimidade de regimes jurídicos opressores como o regime nazista.

Porém, o que poderia ser uma abertura para a própria discussão da cientificidade ou não do direito, não acontece. Vale dizer que o Direito fica marcado irremediavelmente por esta busca de uma certeza, de um sistema que nos permita antecipar - pela aplicação das normas - a decisão.

Assim, deixamos de perceber, muitas vezes, as estratégias discursivas que nos textos se apresentam de uma forma disfarçada, seja por meio de construções linguísticas, seja por meio da construção de uma decisão que nos leve à construção de imagens que produz essa ilusão de certeza.

Warat (1982, p.49), com muita clareza, sugere que há um sentido político da normatividade e que a epistemologia jurídica oficial, vamos chamá-la aqui também de positivismo, busca disfarçá-la por meio da cientificidade dos discursos que os juristas elaboram em nome da verdade.

Deste modo, propõe que o passo decisivo, para a elaboração de um discurso crítico, seja dado primeiro pela substituição do controle conceitual pela compreensão do sistema de significações e, segundo, pela introdução da temática do poder. (WARAT, 1982, p. 50).

A epistemologia oficial ou o positivismo com sua lógica fechada influi para que o jurista seja visto como um operador dos textos legais e não como um operador das relações sociais.

Nesta realidade, encontramos o silogismo como a melhor estratégia discursiva: tudo parece que decorre da norma; que é uma consequência da interpretação da norma.

Os conceitos, como aponta Warat (1982, p.53), são construídos pela razão como uma tentativa de suprimir das ideias seus vínculos com as representações ideológicas ou metafísicas e com suas relações com o poder. Importante verificar que os conceitos também são empregados estrategicamente.

Uma questão semântica importante que precisa ser tratada aqui é - o que é uma propriedade abandonada? O abandono da propriedade é tratado no Código Civil como uma causa de perda da propriedade. Perde-se a propriedade pelo abandono, estabelece o art. 1.275, III, do Código Civil. Mas como se caracterizar a perda e qual a relação da perda com a ocupação e a invasão de imóveis? 
O tema, abandono da propriedade, que é o objeto principal das ações de reintegração de posse, é tratado de forma superficial e secundária pela quase totalidade dos civilistas. A maioria não ultrapassa uma página de seus manuais para tratar desse assunto, não se vê uma relação desse tema com a própria função social da propriedade e mais ainda com a função social da cidade, trazida na Constituição Federal (CF 1988).

No entanto, o número de ações de reintegração de posse, em que proprietários reivindicam a sua propriedade que foi ocupada ou invadida, é imenso. Só no Estado de São Paulo, em uma pesquisa realizada no sistema de busca de jurisprudência do TJ/SP, tivemos, apenas no ano de 2019, 4.026 acórdãos com o tema "Reintegração de posse ocupação imóvel" e 1.112 acórdãos com o tema "Reintegração de posse invasão imóvel". E no ano de 2020, apesar da pandemia, tivemos para o tema "Reintegração de posse ocupação imóvel", 4.219 acórdãos e para o tema "Reintegração de posse invasão imóvel", 1.120 acórdãos.

A ação de reintegração de posse é o grande instrumento jurídico eleito pelo proprietário para recuperar a posse de seu bem, a despeito da alegação de abandono, que poderia levar à utilização da ação reivindicatória, onde a princípio não se discutiria posse e, assim haveria menos risco da alegação de ausência de posse prejudicar o direito do proprietário. Para o mesmo ano de 2019 a busca pelo tema "Ação reivindicatória ocupação imóvel abandonado" acusou apenas 56 acórdãos e para o ano de 2020, acusou 74.

Disso, advém que tanto a propriedade pública como a propriedade privada são frequentemente invadidas ou ocupadas, quer seja por particulares, ou por grupos, ou por movimentos sociais.

Esse tema ganha a página de jornais, visto que é alvo, muitas vezes, de lutas violentas para retomada do bem. Há também projetos de lei para criminalizar os movimentos sociais que ocupam imóveis como se fossem terroristas ${ }^{4}$ e, no entanto, o máximo que os civilistas conseguem é dizer que o abandono é ato unilateral que exige a intenção do proprietário.

Confronta-se, nessas ações, a propriedade e a posse, que ainda põe em evidência a falta de moradia nas cidades, já que essa posse é exercida pela moradia.

\footnotetext{
${ }^{4}$ Temos alguns projetos de lei tramitando na Câmara dos Deputados que buscam criminalizar o ato de ocupação de imóveis, alguns, inclusive, propondo alteração da lei anti-terrorismo, como o projeto de lei 9.604/2018 de autoria do Deputado Jerônimo Goergen (PP/RS), que inclui o § 3ㅇa ao art. 2o da referida lei, cujo texto deixa claro seu propósito: "§3ㅇ 0 disposto no parágrafo anterior não se aplica à hipótese de abuso do direito de articulação de movimentos sociais, destinado a dissimular a natureza dos atos de terrorismo, como os que envolvem a ocupação de imóveis urbanos ou rurais, com a finalidade de provocar terror social ou generalizado". Além desse, também há o PL no 10.010/2018 de autoria do Deputado Nilson Leitão (PSDB/MT), o PL 9.858/2018 de autoria do deputado Rogério Marinho e o PL 5.327/2019 de autoria do deputado José Medeiros.
} 
A redução do tema do abandono da propriedade pelos civilistas a um mero conceito de ato unilateral com ânimo de abandonar, com intenção de não mais tê-la consigo, não permite discutir o sentido político dessa construção, suprime-se das ideias, como revela Warat (1982, p. 53), "seus vínculos com as representações ideológicas e com suas relações com o poder".

Esse conceito de abandono como ato unilateral com intenção de abandonar só justifica e reforça a propriedade liberal, desfuncionalizada, como direito individual de seu proprietário que exerce seu feixe de poderes de forma absoluta.

Prova disso é que até hoje encontramos autores respeitadíssimos, civilistas, cujos manuais são adotados em todas as faculdades do Brasil, que, além de afirmar que o abandono é um ato unilateral que exige intenção, afirmam que o desuso e a negligência não são abandono. ${ }^{5}$

Isso ocorre mesmo com o fato de a Constituição Federal (CF) estabelecer, em seu art. 182, $\S 4$, que é facultado ao Poder Público municipal, mediante lei específica para área incluída no plano diretor, exigir, nos termos da lei federal, do proprietário do solo urbano não edificado, subutilizado ou não utilizado, que promova seu adequado aproveitamento, sob pena de sofrer as sanções estabelecidas em seus incisos, entre estas a desapropriação.

Alexandre Bernardino Costa e Rafael de Acypreste (2018, p. 1824-1867), analisando as ações de reintegração de posse propostas contra o movimento dos trabalhadores sem teto (MTST) no período entre 2001 a 2014 em todos os Estados do Brasil em que o movimento atua, concluíram, em uma profunda análise de dados das decisões, que o Poder Judiciário desconsidera o interesse social subjacente aos processos, para proteger a propriedade em seu formato liberal e absoluto.

Também uma pesquisa coordenada por Betânia de Moraes Alfonsin (2016), no Tribunal de Justiça do Rio Grande do Sul, no período de 2011-2015, concluiu que, apesar de terem se passado 15 anos da publicação do Estatuto da Cidade, revelou-se uma tímida recepção da nova ordem jurídica urbanística nas decisões judiciais envolvendo pesquisas com palavras chaves como "plano diretor", "direito à cidade", "função social da propriedade urbana", reforçando o que os autores chamam de "modelo proprietário", seguida pela ideia de que a concretização de direitos sociais não é tarefa do judiciário, mas do executivo.

\footnotetext{
5 “[...] o mero desuso não importa em abandono; fundamental é a sua conjugação ao elemento psíquico, na perquirição do real interesse do titular de se desfazer da propriedade." (FARIAS; ROSENVALD, 2019, p. 541). "A conduta do proprietário caracteriza-se, neste caso, pela intenção (animus) de não mais ter a coisa para si. Simples negligência não configura abandono, que não se presume" (GONÇALVES, 2012, p. 333). "Um dos motivos da dificuldade em se aferir a intenção de abandono do bem imóvel é o fato de estar contido no poder de uso assegurado pelo art. 1.228 do Código Civil o direito ao não uso do bem [...]." (MELO, 2015, p. 209). "O proprietário deixa a coisa com a intenção de não mais tê-la consigo, surgindo o conceito de res derelicta, diante da derrelição." (TARTUCE, 2015, p. 210).
} 
O que vai definir a perda da propriedade e o direito de ocupá-la é ideológico - não é conceitual - mas a epistemologia dos conceitos não permite discutir o sentido político do saber do direito, já que "os conceitos são construídos pela razão como uma tentativa de suprimir das ideias seus vínculos com as representações ideológicas ou metafisicas e com suas relações com $Q$ poder" (WARAT, 1982, p.53).

É isso que não aparece nas decisões e que o senso comum teórico dos juristas dispensa: o aprofundamento das condições e das relações que tais crenças mitificam. $O$ conhecimento passa a ser purificado pela razão.

\section{A ESTRATÉGIA dO DISCURSO RACIONALMENTE FUNDAMENTADO A PARTIR DA ANÁLISE DE DECISÕES JUDICIAIS SOBRE OCUPAÇÃO / INVASÃO DE IMÓVEIS ABANDONADOS}

As decisões judiciais que envolvem a discussão sobre o ingresso em imóveis abandonados revelam uma ambiguidade: ora o fato é tido como ocupação, ora como invasão; ora o imóvel está abandonado, ora está apenas vazio; ora trata-se de um ingresso legítimo ora de um esbulho.

Há uma construção, por assim dizer, de um silogismo, que fica implícito na conclusão a que se chega a decisão judicial: se o imóvel está abandonado, então o ato de ingressar nele é uma ocupação e, portanto, é legítimo; mas se o imóvel está apenas vazio, desocupado momentaneamente, esse ato é uma invasão e, portanto, é ilegítimo; se o bem é público não há posse, mas sim detenção; se o bem é público e não é possível a posse sobre ele, é irrelevante que esteja abandonado.

Mas como distinguir se a propriedade está abandona ou vazia? E essa distinção decorre de uma norma explícita? E por que sobre o bem público não é possível posse? Por que é irrelevante para o bem público o seu abandono? Quem construiu esses conceitos? Há um conjunto de crenças que parte, inclusive, de normas que não existem, mas, que, quando são aplicadas, parecem que estão sendo extraídos dela.

Como se propõe neste estudo, buscaremos demonstrar que, por trás de um silogismo aparentemente bem construído, há como aponta Warat (1982, p.55), uma apropriação institucional dos conceitos, produzindo-se versões das teorias ajustadas às crenças, às representações e aos interesses legitimadas pelas instituições.

Para além do discurso racional, perfeitamente construído, em que regras são regras e princípios são princípios, em que há apenas uma resposta única, por trás de fórmulas que buscam uma certeza, há uma estratégia discursiva (retórica) presente no discurso jurídico, que procura exatamente a finalidade para a qual sempre existiu: representar uma verdade! 
A separação dos conceitos de suas teorias produtoras permite a constituição de um sistema de verdades, o qual não está vinculado a conteúdos, mas, sim, a procedimentos legitimadores, determinantes para o consenso social. (WARAT, 1982, p. 55)

Não se percebe que há uma apropriação institucional dos conceitos, para exercitar o poder dos significados. Isso se mostra presente na atuação desses profissionais e na construção dessas decisões.

A utilização dos conceitos, desvinculado de suas teorias produtoras permite a constituição de um sistema de verdades que não está vinculado a conteúdos, mas sim a procedimentos legitimadores, determinantes para o consenso social.

Sabemos que toda argumentação é retórica, mesmo a argumentação científica. Mas não é só isso. Não se trata apenas de um uso retórico dessas expressões: ocupação e invasão. As palavras, sabemos, são portadoras de significados, que, em geral estão dicionarizados. Mas além disso, as palavras, com o uso, podem ser permeadas de diversos sentidos que são construídos a partir dos contextos em que são utilizados e de quem os emprega. É claro que, ao dizer que o imóvel foi invadido ou ao dizer que foi ocupado, carregam-se sentidos diversos.

Mas a terminologia utilizada revela além disso, afinal não há inocência na linguagem do direito! Ocupação e invasão buscam representar conceitos, constituir um sistema de verdades. Se o autor afirma que seu imóvel foi invadido, logo deverá ser reintegrado, pois houve um esbulho. Se o réu afirma que ocupou, deverá ser mantido, pois o imóvel estava abandonado.

Mas há um sentido legal para essas expressões? O legislador diferencia as consequências jurídicas? Se o imóvel for ocupado, ao invés de invadido, o tratamento jurídico será diverso? Há diferença entre um imóvel vazio e um imóvel abandonado? Entre um imóvel público e privado? Entre ocupação e invasão?

Em 10 de maio de 2017, o jornal A Gazeta, em sua versão on-line publicou a seguinte matéria: "Juiz autoriza permanência de famílias que ocupam prédio no Centro de Vitória". Esse foi o conteúdo da decisão liminar proferida na Ação de Reintegração de Posse n. 001260097.2017.4.02.5001 ajuizada pela União em face dos ocupantes.

Entre os discursos, a União alegou que o prédio foi invadido por integrantes do Movimento Nacional de Luta pela Moradia e outros e requereu a reintegração de posse no imóvel. Por sua vez, o movimento alegou que não invadiu, mas que ocupou o bem que estava abandonado há mais de 10 anos.

Por outro lado, em 19 de setembro de 2017, o portal G1 noticiou que um prédio abandonado há mais de 4 anos foi invadido por usuários de drogas e moradores de rua, dando o seguinte título à 
sua matéria "Prédio com obra parada há anos é invadido em Jardim Camburi, Vitória". (ALVARENGA, 2017).

O que faz esses casos serem diferentes?

Em ambos, o prédio - objeto da discussão - estava reconhecidamente abandonado. No primeiro, a propriedade era pública e, no segundo, privada, mas o primeiro foi tratado como uma ocupação e o segundo como uma invasão.

Esse embate tem ocorrido com muita frequência. Temos assistido cotidianamente notícias de imóveis abandonados que foram ocupados por grupos de pessoas.

Há algum tempo, 07 de novembro de 2011, um imóvel público da Prefeitura de São Paulo foi ocupado por integrantes de movimentos sem teto. Estes alegaram que o imóvel estava abandonado, e a Prefeitura que ajuizou a ação de reintegração de posse n. 0045635-59.2011.8.26.0053, alegando que não havia abandono e que o imóvel havia sido invadido.

A decisão de primeira instância reconheceu o direito desses ocupantes permanecerem no bem, mas a decisão da instância superior não viu desta forma e determinou a desocupação do bem, considerando que houve a invasão do bem público, como se vê a seguir:

POSSESSÓRIA. Capital. Bem público. Imóvel desapropriado e em seguida invadido por um grupo de pessoas. Direito à moradia. Projeto de implantação da Escola Circo Piolim. 1. Bem público. Posse. Os imóveis foram desapropriados para implantação de serviço de interesse público afeto à Secretaria Municipal da Cultura; são bens públicos dominiais que afastam a posse ou direito de terceiros. Comprovado o arrombamento, a invasão e o uso privado do bem, sem fundamento em lei ou contrato, a concessão da reintegração imediata na posse é de rigor. 2. Colisão de direitos. 0 direito à moradia e o direito de propriedade não são colidentes; são complementares, uma vez que um e outros são exercidos na forma da lei. Inexistência de dispositivo ou princípio constitucional que assegure a apropriação privada de bem público para satisfação imediata de interesse particular, ainda que meritório. 3. Realocação dos moradores. Descabe condenar o município a realocar os moradores. É providência que ofende a separação dos poderes, implica em gastos públicos cuja precedência cabe ao executivo definir e onera o erário com uma despesa a que não deu causa. Improcedência. Recurso do Município e reexame providos para julgar a ação procedente.

Veja que a decisão enfatiza a invasão do bem e, assim, coloca os ocupantes como esbulhadores, sem proteção legal.

Já a decisão liminar no processo no 0012600-97.2017.4.02.5001, proposta pela União em face do Movimento Nacional de Luta por moradia, manteve os ocupantes do imóvel, considerando o abandono do bem há muitos anos e, sendo o bem público, condicionou a retirada dos moradores desde que houvesse a colocação dessas pessoas em moradias oferecidas pelo Poder Público: 
É certo que a posse real e a propriedade da União sobre os bens públicos é tutelada pelo Código Civil, e merece proteção jurisdicional. Ocorre que, no caso, entendo ser possível relativizá-la provisoriamente, em face do direito de moradia, ante a já ressaltada relevância deste na hipótese concreta. Soma-se a isso o fato de que o bem público ora discutido encontra-se trancado desde o ano de 2010 (fl. 07), sem qualquer afetação para a concretização das finalidades públicas, sendo tal fato público e notório, de forma que a manutenção provisória dos indivíduos no local não prejudicará a execução de serviços públicos. ${ }^{6}$

O embate é sempre colocado desta forma: de um lado, a alegação de invasão; de outro, a de ocupação | de um lado, a alegação de desocupação do imóvel; de outro, a de abandono | de um lado, a alegação de esbulho; de outro, a de ocupação | de um lado, o bem público; de outro, o bem privado.

Ocupamos espaços discursivos diferentes, quando optamos pelo uso das expressões, porque isso se altera de acordo com o que queremos trazer para o processo de convencimento.

Prova disso é que o Movimento dos trabalhadores sem teto (MTST) repudia a palavra invasão para seus atos. Seu líder Guilherme Boulos, em entrevista ao jornal O Estado de São Paulo, em 06 de julho de 2014 (PEREIRA) e, também, em um vídeo produzido pela Mídia Ninja, intitulado "Por que ocupamos", denomina como ato de ocupação a ação do movimento, buscando distinguir o ato de invadir e o ato de ocupar:

Invadir, como costuma usar aqui o Estado, se referiria a você entrar em um lugar que já está ocupado por alguém. Invadir é o que os Estados Unidos fizeram no Iraque. Chegar com tropas e matar. É o que Israel faz na Palestina, na Faixa de Gaza, na Cisjordânia. Isso é invadir. Ninguém vai chegar na tua casa e dizer: estamos entrando aqui. Isso é invadir. Isso o MST não faz. Ocupar é tomar lugares ociosos. ${ }^{7}$

Mas por que essa necessidade de diferenciar linguisticamente esses atos? Por que entrar em uma propriedade alheia pode ser invadir ou ocupar? Há diferença entre o imóvel abandonado ou

\footnotetext{
${ }^{6}$ A decisão determinou à União e aos ocupantes que: “c) Envidem esforços para que a desocupação do imóvel ocorra de forma a preservar os direitos constitucionais das pessoas que ali se encontram, devendo estas ser realocadas em locais adequados à sua sobrevivência digna. No pormenor, a União e o Movimento poderão solicitar o apoio de outros órgãos e entes públicos, em especial do Município de Vitória e DPU e MPF. d) Tragam aos autos um plano de desocupação coordenado, com previsão de datas de desocupação e realocação das famílias que realmente não possuem moradia, em auxílio, se for o caso, do Município de Vitória e DPU e MPF, entre outros órgãos". (Brasil. Tribunal Regional Federal (2ª Região). 3a Vara Cível. Ação de Reintegração de Posse no 0012600-97.2017.4.02.5001 (2017.50.01.012600-0). Juiz Luís Fernando Camargo de Barros Vidal. Vitória, 2012 https://eproc.jfes.jus.br/eproc/controlador.php?acao=acessar_documento\&doc=501576 438937387311931605886699 \&evento $=501576438937387311931605940714 \&$ key $=219193$ ed6665ac6222e160 d65d4b4c54d607cfd8804527939a2703e45e3040d8\&hash=be1bd8b1c0c93ea2578c40cb4524dca7. Acesso em: 13 jul. 2020.

7 BOULOS, Guilherme. Por que ocupamos? Midia Ninja. You Tube. Disponível em: https://www.youtube.com/watch?v=H8-02_JulLo. Acesso em 20 ago. 2021.
} 
vazio? Há diferença entre ingressar em um imóvel público ou privado, quando o imóvel está abandonado?

Vejam que essas decisões fazem pouca ou quase nenhuma referência à norma, não há uma dedução de um texto legal, que faça decorrer essa conclusão. Na verdade, o conceito é construído para a conclusão, pois é a decisão que impõe a construção do conceito e não o contrário (mas deixaremos para concluir isso mais à frente, ao proteger a propriedade liberal, o conceito passa a ser "ingressar em propriedade é esbulho", mas, ao proteger a posse o direito social à moradia, o conceito passa a ser "se o imóvel estiver abandonado, a ocupação é um ato lícito").

Se não há uma norma explícita, como querem os intérpretes, se não são princípios para haver uma colisão entre estes a justificar uma ponderação, então em que campo estamos?

Veja a ementa desta decisão que chamaremos de D1:

AÇÃO DE REINTEGRAÇÃO DE POSSE. IMÓVEL PÚBLICO DE USO COMUM. [...]. AJUIZAMENTO DE DEMANDA POSSESSÓRIA QUE PRESCINDE DE PRÉVIA INSTAURAÇÃO DE PROCEDIMENTO ADMINISTRATIVO. UTILIZAÇÃO DOS ELEMENTOS COLHIDOS NO PROCEDIMENTO APENAS COMO ELEMENTOS DE INFORMAÇÃO. TEORIA DA DESCOBERTA INEVITÁVEL POR FONTE INDEPENDENTE EM CIDADE DE GRANDE PORTE, AO LADO DE UM VIADUTO. TITULARIDADE PÚBLICA DO IMÓVEL E ESBULHO PELO RÉU. FATOS INCONTROVERSOS. DESCASO DO MUNICÍPIO PARA COM SEU IMÓVEL. OMISSÃO QUE CONFERE AOS VIZINHOS E CIDADÃOS INTERESSADOS A POSSIBILIDADE DE CUIDAR E REALIZAR A MANUTENÇÃO NECESSÁRIA DO BEM PÚBLICO DE USO COMUM, DESDE QUE PRESERVADA A FINALIDADE PÚBLICA PRÓPRIA DO IMÓVEL. SITUAÇÃO QUE NÃO SE CONFUNDE COM O EXERCÍCIO DE POSSE DE MANEIRA EXCLUSIVA POR PARTICULARES SOBRE O IMÓVEL PÚBLICO. DEFORMAÇÃO DA FINALIDADE PÚBLICA DO IMÓVEL. OCUPAÇÃO COM EXCLUSIVIDADE QUE AFASTA A POSSIBILIDADE DE USO COMUM DO BEM. OCUPAÇÃO INDEVIDA. APELAÇÃO DESPROVIDA. 1. [...] 2. [...] 3. O fato do Município proprietário não tomar os cuidados necessários para a manutenção do terreno, ainda que por anos, não autoriza os vizinhos ou quem quer seja a ingressar no imóvel público de uso comum e passar a possuí-lo com exclusividade. Não existe um direito de invadir o terreno público, mesmo frente ao abandono do proprietário em relação aos cuidados básicos com o imóvel. 4. O que existe, isto sim, é a possibilidade dos vizinhos ou interessados tomarem as providências adequadas para impedir que o desleixo do ente público proprietário em relação ao terreno abandonado prejudique sua saúde, tranquilidade ou a utilização adequada de seus próprios imóveis - como carpir o local, revitalizá-lo ou fazer sua manutenção -, com posterior ressarcimento, a depender do caso, pelo proprietário do imóvel abandonado (ente público) dos valores dispendidos para tanto, por meio do instituto da gestão de negócio alheio sem mandato (arts. 868 a 870 do CCB).

Há uma série de referências implícitas nesse discurso jurídico, muitas premissas encontramse implícitas, como também implícitas estão diversas normas, que, na análise geral, nos levam a uma ideia de explicitude, quando não são explícitas, nem estão implícitas. 
Quais as sentenças que se extraem dessa decisão:

a. Um imóvel não cuidado durante anos, não implica que foi abandonado.

b. O imóvel abandonado não autoriza o ingresso.

c. Não é possível - mesmo diante do abandono - o exercício de posse com exclusividade por terceiros.

d. Não há um direito de invadir imóvel público, mesmo abandonado.

e. Existe o direito dos vizinhos e dos interessados tomarem providências adequadas para impedir o desleixo do imóvel público, que prejudique sua saúde e tranquilidade.

f. Os vizinhos podem se ressarcir do proprietário do imóvel (público) pelas despesas com sua conservação.

É curioso que não há uma referência à norma legal, ela, em momento algum, é citada, ou mesmo explicitada. No entanto, a leitura da decisão nos dá uma sensação de completude e coerência lógica, como se houvesse deduções extraídas de um texto legal.

$\mathrm{E}$, mais que isso, essas deduções parecem ser universais, como se derivassem de uma norma legal explícita que conduzisse, necessariamente, a essa conclusão.

Mas analisando outras decisões envolvendo a mesma situação fática - ingresso em imóvel alheio - percebe-se que a conclusão é diferente, mas a estratégia discursiva é a mesma.

Sobota (1996) sugere que, na retórica legal cotidiana, é característica legal das normas utilizadas que elas somente existam na esfera da alusão ou da implicação.

Com efeito, a primeira vantagem, de acordo com a autora, é que se os juízes e os advogados não verbalizam as premissas maiores alegadas, eles podem ocultar a inconsistência de todo o sistema normativo. A segunda vantagem, por sua vez, é que um orador pode modificar o significado alegado da norma e adaptá-lo a cada situação. Já a terceira vantagem é que normas tácitas podem formar um elo entre o mundo arcaico das regularidades emotivas, não-verbalizadas, e a racionalidade verbalizada do ocidente clássico. (SOBOTA, 1996, p. 55)

Veja, nesta segunda decisão, denominada de D2:

INGRESSO EM IMÓVEL ABANDONADO. AUSÊNCIA DO VÍCIO OBJETIVO DA CLANDESTINIDADE. PUBLICIDADE DA AÇÃO. POSSE JUSTA. ESBULHO DESCARACTERIZADO. FUNÇÃO SOCIAL DA POSSE. DIREITO CONSTITUCIONAL À MORADIA. DIGNIDADE DA PESSOA HUMANA. 1. Nas ações possessórias vedase a discussão de domínio, já que a causa de pedir e o pedido devem versar exclusivamente sobre posse, independentemente da alegação de propriedade ou de outro direito sobre a coisa. 2. No juízo possessório, portanto, não poderá o juiz conhecer da alegação, em defesa, do direito de propriedade (exceção de domínio), operando-se assim, uma total separação, no direito vigente, entre ius possessionis e ius possidendis. 3. O ingresso público e ostensivo em imóvel abandonado, no qual o atual possuidor constrói sua residência concedendo ao bem função social, descaracteriza o vício objetivo da clandestinidade e afasta, consequentemente, a alegação de esbulho. 4. Em circunstâncias tais, a posse insere-se entre os direitos da personalidade, na medida em que concede efetividade ao direito social à moradia (artigo 6o da Constituição Federal) e 
oportuniza ao cidadão, acesso a bens vitais mínimos capazes de conferir dignidade à pessoa humana (artigo 1으, inciso III, da Constituição Federal), fomentando consequentemente, o desenvolvimento da entidade familiar. 5. Recurso conhecido e provido. Sentença reformada.

As sentenças que se extraem dessa decisão são:

a. Ingressar em imóvel abandonado é legítimo.

b. Ingressar em imóvel abandonado, de forma pública e ostensiva, não caracteriza esbulho.

c. Não é possível discutir propriedade no juízo possessório.

d. A posse insere-se entre os direitos da personalidade

e. Quando a posse em imóvel abandonado visa à residência familiar, atende ao direito social à moradia (Art. 6으)

f. A moradia é um direito social que garante acesso a bens vitais mínimos capazes de conferir dignidade à pessoa humana.

Veja que, novamente, não há referência a uma norma legal explícita de onde se possa extrair a conclusão da decisão. Mas, outra vez, parece que tudo adquire uma consistência lógica e coerente e, apesar de não haver referência a esta norma legal explícita, surgem diversas normas implícitas, como também a vantagem, apontada por Sobota (1996), de o orador modificar o significado alegado da norma adaptando-o a cada situação. Veja que, na D1, o abandono do imóvel não é razão para seu ingresso, pelo contrário, o ingresso em imóvel abandonado caracteriza invasão; já, na decisão D2, o abandono do imóvel autoriza o seu ingresso e, sendo esse ingresso público e ostensivo, não caracteriza esbulho e ainda, quando o possuidor constrói ali a sua residência e atende ao direito social à moradia, deve ser mantido no bem, pois cumpridor de sua função social.

Além disso, como a terceira vantagem apontada por Sobota, há a construção de um elo "sentimental" do fato e da norma. Afinal, na D2, recorre-se a sentimentos morais, pois há a valoração da moradia no bem alheio - mas abandonado - sobre a proteção da propriedade abandonada.

Num país com tantas pessoas sem lares, vivendo na rua, o apelo a esse sentimento humanitário é uma estratégia retórica, discursiva, muito importante para construção desse conceito.

Veja como, em diversas decisões, esse elemento ganha mais destaque do que a própria referência aos textos legais de onde essas conclusões parecem ser extraídas.

Nesse trecho da sentença de 1o grau, proferida pelo juízo da 3ạ Vara da Fazenda Pública de São Paulo, que chamaremos D3, esse elemento ganha destaque:

O poder público municipal encontra-se em inescusável mora com a realização do direito social fundamental de habitação, e pretende destinar um conjunto de prédios para a instalação de equipamento cultural que poderia ser alocado numa lona, e posterga uma solução razoável para a situação de privação de direitos do conjunto da população que ali acode, recusando-se a qualquer forma de diálogo construtivo, dando assim, ensanchas para que o 
comportamento dos requeridos seja considerado como de exercício do direito fundamental de resistência por meio do qual questionam a injustiça da opção administrativa e sua desconformidade com a precedência e a prevalência do direito fundamental. Neste panorama, a propriedade pública aflora desfuncionalizada, e sua posse se afigura capenga, cedendo àquela dos requeridos porque assentada no melhor título jurídico que é o direito social à habitação, não havendo que se protegê-las à conta de uma certidão imobiliária. A dimensão publicística do conflito exige solução diversa da proteção possessória do direito privado, e autoriza o acolhimento da exceção do contrato social não cumprido." (grifo nosso)

Mas esse mesmo elemento não é considerado nesta outra decisão (D4), que, pelo contrário, utiliza-o, mas rechaça-o, pois fica a impressão de uma decisão fria, insensível.

AGRAVO DE INSTRUMENTO - NÃO CONHECIMENTO POR DESCUMPRIMENTO DO ART. 526 DO CPC - INADMISSIBILIDADE - AUSÊNCIA DE PREJUÍZO DO CONTRADITÓRIO DA PARTE ADVERSA - REJEIÇÃO DA PRELIMINAR ARGUIDA PELA AGRAVADA. JUSTIÇA GRATUITA - PEDIDO PENDENTE DE APRECIAÇÃO EM PRIMEIRO GRAU NOS AUTOS DA AÇÃO PRINCIPAL - NÃO CONHECIMENTO DA MATÉRIA, SOB PENA DE SUPRESSÃO DE INSTÂNCIA. POSSE - LIMINAR EM AÇÃO DE REINTEGRAÇÃO DE POSSE - CABIMENTO - Réus são integrantes do "Movimento dos Sem Teto", cuja ilegal ocupação de áreas se sustenta invariavelmente na surrada composição teórica da "função social da propriedade" - Teoria que não elimina o princípio constitucional de proteção à propriedade - É a lei, não a vontade de um grupo de pessoas, que estabelece os mecanismos para se impor sanção à propriedade que não cumpre a função social - Ocupação do imóvel por várias famílias humildes Irrelevância - Questão social que deve ser solucionada pelas autoridades competentes e não torna lícita a ocupação - A Constituição Federal, embora consagrando a finalidade social da propriedade (cf. art. 184), não derrogou as normas de proteção ao direito de posse - Fato social não deve ser resolvido pelo particular, mas pelo Poder Público, que o faz, de ordinário, mediante tributação progressiva da propriedade ou desapropriação. Recurso conhecido em parte e desprovido na parte conhecida." (grifo nosso)

Com relação a imóvel público, fica claro que é necessária a construção de um conceito estratégico para justificar uma leitura ideológica da propriedade pública e, assim como aponta Warat (1982, p.53), resolver idealmente o conflito entre a teoria e a prática, ignorando o valor político do conhecimento na práxis, deste modo o jurista de ofício não é visto como um operador das relações sociais, mas sim como um operador técnico dos textos legais, mesmo que os textos legais nem digam isso, mas, dessa forma, cria-se a ilusão de atividade profissional pura.

Isso é evidente na ementa dessa decisão D5, como se vê:

AÇÃO DE INDENIZAÇÃO POR DANOS MORAIS E MATERIAIS CONSTRUÇÃO IRREGULAR EM ÁREA PÚBLICA Demolição determinada - Bem público que não induz posse a favor do particular, que sobre ele exerce mera detenção Irrelevância de boa-fé - Utilização de critérios de proporcionalidade e ponderação, na colisão entre direitos fundamentais Indevida indenização por 
quaisquer danos - Natureza de construção irregular em área pública, o que não configura posse, nem autoriza benfeitorias, por mera inércia do Poder Público Dano material indevido - Dano extrapatrimonial que não se configurou, vez que a conduta da Municipalidade não apresenta nexo de causalidade a ensejar o resultado danoso vivenciado pelo autor, que, por si, edificou em área pública, sem autorização, restando sujeito, portanto, aos riscos inerentes a tal ato Sentença de improcedência mantida - Precedentes Apelo desprovido".

Quais as sentenças que se extraem dessa decisão:

a. Não há posse sobre imóvel público.

b. A ocupação de bem público considera-se detenção.

c. É irrelevante a boa-fé dos ocupantes.

d. Como detenção, não há direito à indenização de acessões e de benfeitorias.

e. A ocupação de bem público é um risco assumido pelo ocupante que não the garante indenização.

Por sua vez, na decisão D6, alterando o posicionamento jurídico até então dominante, entendeu que é possível posse sobre bem público, quando a disputa ocorre entre particulares.

BEM PÚBLICO DOMINICAL. LITÍGIO ENTRE PARTICULARES. INTERDITO POSSESSÓRIO. POSSIBILIDADE. FUNÇÃO SOCIAL. OCORRÊNCIA. 1. Na OCUPação de bem público, duas situações devem ter tratamentos distintos: i) aquela em que o particular invade imóvel público e almeja proteção possessória ou indenização/retenção em face do ente estatal e ii) as contendas possessórias entre particulares no tocante a imóvel situado em terras públicas. 2. A posse deve ser protegida como um fim em si mesma, exercendo o particular o poder fático sobre a res e garantindo sua função social, sendo que o critério para aferir se há posse ou detenção não é o estrutural e sim o funcional. É a afetação do bem a uma finalidade pública que dirá se pode ou não ser objeto de atos possessórias por um particular. 3. A jurisprudência do STJ é sedimentada no sentido de que o particular tem apenas detenção em relação ao Poder Público, não se cogitando de proteção possessória. 4. É possível o manejo de interditos possessórios em litígio entre particulares sobre bem público dominical, pois entre ambos a disputa será relativa à posse. 5. À luz do texto constitucional e da inteligência do novo Código Civil, a função social é base normativa para a solução dos conflitos atinentes à posse, dando-se efetividade ao bem comum, com escopo nos princípios da igualdade e da dignidade da pessoa humana. 6. Nos bens do patrimônio disponível do Estado (dominicais), despojados de destinação pública, permite-se a proteção possessória pelos ocupantes da terra pública que venham a lhe dar função social. 7. A ocupação por particular de um bem público abandonado/desafetado - isto é, sem destinação ao uso público em geral ou a uma atividade administrativa -, confere justamente a função social da qual o bem está carente em sua essência. 8. A exegese que reconhece a posse nos bens dominicais deve ser conciliada com a regra que veda o reconhecimento da usucapião nos bens públicos (STF, Súm 340; CF, arts. 183, § $3^{\circ}$; e 192; CC, art. 102); um dos efeitos jurídicos da posse - a usucapião - será limitado, devendo ser mantido, no entanto, a possibilidade de invocação dos interditos possessórios pelo particular. 9. Recurso especial não provido". 
A partir dessa decisão, podemos extrair as seguintes sentenças:

a. Quando o particular ingressa em imóvel público, isso é invasão.

b. Não há posse de particular frente ao poder público.

c. Há posse entre particulares de bem público dominial.

d. Há posse de imóvel público dominial que não esteja afetado a um serviço público.

e. Essa posse só é reconhecida quando houver uma disputa entre particulares e não entre o particular e o poder público.

f. A função social é base normativa para os conflitos atinentes à posse, desde que a disputa possessória seja entre os particulares e não entre o particular e o poder público.

O que se percebe é que não há uma coerência no todo, o que há são construções discursivas, para tornar coerente e lógica uma dada decisão judicial. Há uma verdade construída que se utiliza desse aparelhamento positivista, por meio desses silogismos, criando a ilusão de uma atividade profissional pura. Parece, como já dissemos, que tudo que se faz é aplicar a norma, mesmo que não se tenha norma!

Se o imóvel foi abandonado, então o ingresso foi uma ocupação e não uma invasão, logo é lícito; se o imóvel não está abandonado, então o ingresso foi uma invasão, logo é um ilícito um esbulho; se o imóvel é público, não há posse e sim detenção, mas, se a disputa possessória do bem público for entre dois particulares, é possível falar em posse e em função social.

Mas esse silogismo não aparece explicitamente na decisão, até porque não há uma norma que a explicite. Então, iremos perceber que as decisões criam essa ilusão de certeza, ocultando muito dessas premissas, que se tornam apenas implícitas, sem sequer haver referência aos textos legais (1aㅡ vantagem), adaptando o significado da norma a cada situação (2 ${ }^{\text {a }}$ vantagem) e ainda recorrendo-se a normas tácitas, a conteúdos morais, que vão estabelecer esse elo entre a emoção e a razão ocidental (3a vantagem).

\section{EM BUSCA DO SABER CRÍTICO: UMA TENTATIVA DE CONCLUSÃO}

Ao longo deste artigo, buscamos demonstrar que o senso comum em nome da cientificidade do discurso jurídico constrói verdades, mas é preciso reconhecer os limites, os silêncios e as funções políticas da epistemologia oficial se buscamos um conhecimento crítico do direito. (WARAT, 1982, p. 49)

Demonstramos, a partir das lições de Sobota (1996), que uma das estratégias discursivas das decisões judiciais que envolve o ingresso de pessoas em imóveis desocupados com intenção de moradia, é a aparente construção de um silogismo jurídico, deixando implícitas as normas legais que são estabelecidas como premissas. 
Mas qual seriam então essas normas legais da qual se deduzem essas conclusões contraditórias numa análise geral, mas coerentes numa análise particular? A primeira norma a ser mencionada é o art. 1.275 , III, do CC, que estabelece a perda da propriedade pelo abandono. ${ }^{8}$

Ainda sobre o abandono, prevê o art. 1276 do CC a possibilidade de arrecadação pelo poder público nas condições ali estabelecidas:

O imóvel urbano que o proprietário abandonar, com a intenção de não mais o conservar em seu patrimônio, e que se não encontrar na posse de outrem, poderá ser arrecadado, como bem vago, e passar, três anos depois, à propriedade do Município ou à do Distrito Federal, se se achar nas respectivas circunscrições.

$\S 1$ 으 imóvel situado na zona rural, abandonado nas mesmas circunstâncias, poderá ser arrecadado, como bem vago, e passar, três anos depois, à propriedade da União, onde quer que ele se localize.

$\S 2$ o Presumir-se-á de modo absoluto a intenção a que se refere este artigo, quando, cessados os atos de posse, deixar o proprietário de satisfazer os ônus fiscais.

Em nenhuma das decisões aqui selecionadas, houve referência a esses artigos legais, no entanto a discussão sobre o abandono e o ingresso no imóvel alheio estiveram presentes.

A D1 sentenciou expressamente que o abandono de um imóvel não autoriza o ingresso por terceiros, sendo este ato ilícito.

Já a D2, em sentido contrário, estabeleceu o direito de o possuidor ocupar um imóvel abandonado e ali permanecer, quando sua finalidade for a moradia.

$\mathrm{O}$ direito à moradia foi referido em algumas dessas decisões. Esse direito social é previsto no art. 6o da CF: São direitos sociais a educação, a saúde, a alimentação, o trabalho, a moradia, o transporte, o lazer, a segurança, a previdência social, a proteção à maternidade e à infância, a assistência aos desamparados, na forma desta Constituição.

Também é previsto na CF a função social da propriedade (art. 5o, XXIII) e o direito de propriedade (art. 5ㅇ, XXII).

Outra norma legal, que está implícita, em algumas dessas decisões, é o conceito de posse injusta do art. 1.200 do CC: "É justa a posse que não for violenta, clandestina ou precária".

Outra norma que parece inferir-se das decisões é o art. 1.210 do CC: O possuidor tem direito a ser mantido na posse em caso de turbação, restituído no de esbulho, e segurado de violência

\footnotetext{
8 "Além das causas consideradas neste Código, perde-se a propriedade: III- por abandono." BRASIL. Lei n.으 10.406, de 10 de janeiro de 2002. Institui o Código Civil. Disponível em: <http://www.planalto.gov.br/ccivil_03 /leis/I7783.htm>. Acesso em: 27 jan. 2019.
} 
iminente, se tiver justo receio de ser molestado. Complementado pelo art. 560 do CPC: O possuidor tem direito a ser mantido na posse em caso de turbação e reintegrado em caso de esbulho.

Mas todas estas normas não levam a um silogismo em que se possa, aplicando-se a premissa maior (norma) e a premissa menor (fato), deduzir sua conclusão.

Já com relação à propriedade pública, não há nenhuma norma que a diferencie da propriedade privada, a não ser a impossibilidade de usucapi-la. Qual a norma que define que a ocupação de um bem público é detenção e não posse?

Veja que, na D5, não há nenhuma referência ao texto legal, apenas se constrói um conceito e dele se deduz uma interpretação ideológica da propriedade pública para beneficiar o poder público.

Toda construção jurídica sobre a detenção de bem público é feita univocamente pelos tribunais e repetidas como uma crença legal, quando muito se tenta comparar com alguma espécie de detenção. Mas nem na D4, nem na D5, faz-se referência ao art. 1.198 ou 1.208 que estabelecem no CC as hipóteses de detenção. ${ }^{9}$

Os conceitos têm uma finalidade, que é suprimir o sentido político do saber do Direito, são, como afirma Warat, construídos pela razão como uma tentativa de suprimir das ideias seus vínculos com as representações ideológicas. Não se analisa seu emprego estratégico na práxis, que é exatamente isso que ocorre, há um jogo estratégico, em que esses conceitos são reapropriados e convertidos em significações. (1982).

Então, voltando à pergunta do início desse texto: qual a diferença entre ocupar e invadir? É lícito ou não a ocupação de um imóvel desocupado? Os possuidores devem permanecer no bem, pois o seu direito à moradia deve ser garantido? Num sistema legal de construção positivista, há sempre a busca pela norma. O que a norma diz? É justamente em virtude da busca de uma norma que possa conduzir a uma resposta, que a decisão judicial se apresenta sob a forma de um silogismo, assim parece que tudo não passa de uma dedução, quando é uma construção bem elaborada que se utiliza de diversas estratégias retóricas.

Neste texto, propusemo-nos a analisar a escolha de certas expressões (ocupação X invasão; imóvel vazio X imóvel abandonado) - que repercutirão conceitos moldados para justificar aquele objetivo.

\footnotetext{
9 "Art. 1.198. Considera-se detentor aquele que, achando-se em relação de dependência para com outro, conserva a posse em nome deste e em cumprimento de ordens ou instruções suas." "Art. 1.208. Não induzem posse os atos de mera permissão ou tolerância assim como não autorizam a sua aquisição os atos violentos, ou clandestinos, senão depois de cessar a violência ou a clandestinidade". BRASIL. Lei n.o 10.406, de 10 de janeiro de 2002. Institui o Código Civil. Disponível em: Disponível em: https://www.planalto.gov.br/ccivil 03/LEIS/2002/L10406.htm. Acesso em: 19 jul. 2020.
} 
Assim, se pretendo ou se entendo que um imóvel abandonado não cumpre sua função social e que, por isso, a posse ali exercida deve ser protegida, elaboro esse jogo linguístico, fazendo essas construções, que não são decorrências do texto legal, pois a norma não é explícita.

Veja o caso do abandono da propriedade - ponto central do nosso problema. Diz a norma: a propriedade se perde pelo abandono. Mas isso não resolve a situação dos ocupantes, daqueles que ali ingressaram. Pelo menos não a princípio.

Para se concluir que a posse deles deve ser protegida, em detrimento da propriedade que foi abandona, há toda uma outra elaboração, de diversas outras normas, que ficam implícitas na decisão, além da utilização de valores sociais e morais.

Da mesma forma, quando se quer proteger a propriedade, a despeito do seu abandono, não se deixa explícito o abandono, utilizando-se de expressões como imóvel vazio, desocupado; reforçase o caráter ilícito do ingresso em imóvel alheio e, também, se utiliza de valores sociais, como a violência da invasão, a imagem negativa desses grupos que realizam tais atos.

Por último, como essa ideia positivista é muito forte entre nós, um dos principais métodos do positivismo é o método dedutivo do qual se extrai de silogismos, que nos levam a essa ilusão de certeza. Por isso, a decisão judicial é também construída retoricamente como um silogismo.

A sua leitura parece nos levar a deduzir aquela conclusão, no entanto, como observa Sobota (1996, p.57), as normas utilizadas no processo de decisão judicial são na maior parte alusões, às vezes recheadas de informações sobre a realidade social, mas, às vezes, também reduzidas a uma atribuição geral, a qual pode ser preenchida com sentimentos inexpressáveis, afirmações casuais de valores e de realizações também casuais de modelos estimativos tradicionais.

Assim, para concluir com Warat, os limites, os silêncios e as funções políticas da epistemologia oficial devem ser revelados, por isso é preciso saber e compreender o sentido político da normatividade, se não queremos um conhecimento apolitizado do Direito.

\section{REFERÊNCIAS}

ADEODATO, João Maurício. Uma teoria retórica da norma jurídica e do direito subjetivo. São Paulo: Noeses, 2014.

ALFONSIN, Betânia de Moraes et al. A ordem jurídico-urbanística nas trincheiras do Poder Judiciário. Revista Direito \& Práxis. V. 7. N, n. 14, 2016, p. 421-453.

ALVARENGA, Poliana. Prédio com obra parada há anos é invadido em Jardim Camburi, Vitória. G1. Disponível em: Disponível em https://g1.globo.com/espirito-santo/noticia/predio-com-obra-paradaha-anos-e-invadido-em-jardim-camburi-vitoria.ghtml . Acesso em: 20 ago. 2021. 
BARROS, Aidil de Jesus Paes de; LEHFELD, Neide Aparecida de Souza. Projeto de pesquisa: Propostas metodológicas. 16.ed. Petrópolis, RJ: Vozes, 1990.

BOBBIO, Norberto. O Positivismo Jurídico. Lições de Filosofia do Direito. São Paulo: Ícone Editora, 1996.

BOULOS, Guilherme. Por que ocupamos? Midia Ninja. You Tube. Disponível em: https://www.youtube.com/watch?v=H8-O2_JulLo. Acesso em 20 ago. 2021.

BRASIL. Câmara dos Deputados. Projeto de lei ordinária no 5.327/2019. Trata do abuso do direito de articulação de movimentos sociais, voltado a dissimular atuação terrorista, acrescentando parágrafo ao art. 2을 da Lei no 13.260, de 16 de março de 2016. Disponível em

https://www.camara.leg.br/proposicoesWeb/prop_mostrarintegra?codteor=1814670\&filename=PL+ 5327/2019. Acesso em: 12 de julho dejul. 2020.

BRASIL. Câmara dos Deputados. Projeto de lei ordinária no 9.604/2018. Dispõe sobre o abuso do direito de articulação de movimentos sociais, destinado a dissimular atuação terrorista, inserindo parágrafo no art. 2으 da Lei № 13.260, de 16 de março de 2016. Disponível em:

https://www.camara.leg.br/proposicoesWeb/fichadetramitacao?idProposicao=2168253. Acesso em 13. Jul. 2020.

BRASIL. Câmara dos Deputados. Projeto de lei ordinária no 9.858/2018 Acrescenta os art. 565-A a 565-E à Lei 13.105, de 2015, altera o $\$ 1$ ㅇ do art. 1.212, da Lei 10.406, de 2002, e altera o art. 161 do Decreto-Lei 2.848, de 1940. Disponível em:

https://www.camara.leg.br/proposicoesWeb/fichadetramitacao?idProposicao=2169954. Acesso em: 13. Jul. 2020.

BRASIL. Constituição da República Federativa do Brasil 1988. Disponível em: https://www.planalto.gov.br/ccivil_03/Constituicao/Constituicao.htm. Acesso em: 19 jul. 2020.

BRASIL. Lei n.o 10.406, de 10 de janeiro de 2002. Institui o Código Civil. Disponível em: <http://www.planalto.gov.br/ccivil_03 /leis/17783.htm>. Acesso em: 27 jan. 2019.

BRASIL. Lei no 13.105, de 16 de março de 2015. Código de Processo Civil. Disponível em:

http://www.planalto.gov.br/ccivil_03/_Ato2015-2018/2015/Lei/L13105.htm. Acesso em: 19 jul. 2020

BRASIL. Superior Tribunal de Justiça. Recurso Especial. Processo n. 1.296.964 - DF (2011/0292082-2). Relator Ministro Luís Felipe Salomão. Brasília, 07 dez. 2016. Disponível em:

https://ww2.stj.jus.br/processo/pesquisa/?tipoPesquisa=tipoPesquisaNumeroRegistro\&termo=2011 02920822\&totalRegistrosPorPagina=40\&aplicacao=processos.ea. Acesso em 13. Juljul. 2020.

BRASIL. Tribunal de Justiça de Minas Gerais. Apelação Cível n. 100240586459530011. Relator: Nicolau Masselli. Belo Horizonte, 09 jul. 2009. Disponível em: https://tjmg.jusbrasil.com.br/jurisprudencia/6002631/100240586459530011-mg-1002405864595-3-0011/inteiro-teor-12137917. Acesso em: 19. Juljul. 2020.

BRASIL. Tribunal de Justiça de São Paulo. 3a Vara da Fazenda Pública de São Paulo. Ação de Reintegração de Posse n. 0045635-59.2011.8.26.0053. Juiz Luís Fernando Camargo de Barros Vidal. São Paulo, 21 jun. 2012. Disponível em:

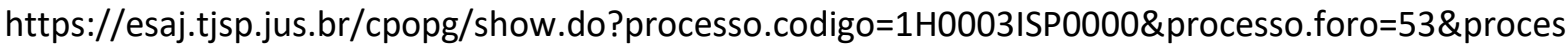
so.numero $=0045635-$ 
59.2011.8.26.0053\&uuidCaptcha=sajcaptcha_6c3d662fa37e4191af9a8a0c075342a2. Acesso em: 13 jul. 2020.

BRASIL. Tribunal de Justiça de São Paulo. 4a Vara Cível da Comarca de Piracicaba. Ação de Reintegração de Posse. Processo n. 1001115-49.2020.8.26.0451. Juíza Fabíola Giovanna Barrea Moretti, 7 mai. 2020. Disponível em:

https://esaj.tjsp.jus.br/cpopg/show.do?processo.codigo=CJ000MME00000\&processo.foro $=451 \&$ proc esso.numero $=1001115$ -

49.2020.8.26.0451\&uuidCaptcha=sajcaptcha_7659fc7cc72d41e6a36685574117f0b6. Acesso em: 13. J jul. 2020.

BRASIL. Tribunal de Justiça de São Paulo. Ação civil pública n. 0000288-77.2014.8.26.0447. Relator: Spoladore Dominguez. São Paulo, 02 mar. 2016. Disponível em https://esaj.tjsp.jus.br/cposg/search.do?conversationld=\&paginaConsulta=0\&cbPesquisa=NUMPROC \&numeroDigitoAnoUnificado $=0000288$ -

77.2014\&foroNumeroUnificado $=0447 \&$ dePesquisaNuUnificado $=0000288$ -

77.2014.8.26.0447\&dePesquisaNuUnificado=UNIFICADO\&dePesquisa=\&tipoNuProcesso=UNIFICADO . Acesso em: 13 jul. 2020.

BRASIL. Tribunal de Justiça de São Paulo. Agravo de Instrumento n. 223532851.2015.8.26.0000.

Relator: Juiz Álvaro Torres Junior. São Paulo, 29 de fevereiro de 2016. Disponível em https://esaj.tjsp.jus.br/cposg/search.do?conversationld=\&paginaConsulta=0\&cbPesquisa=NUMPROC \&numeroDigitoAnoUnificado=2235328-

$51.2015 \&$ foroNumeroUnificado $=0000 \&$ dePesquisaNuUnificado $=2235328-$

51.2015.8.26.0000\&dePesquisaNuUnificado=UNIFICADO\&dePesquisa=\&tipoNuProcesso=UNIFICADO . Acesso em: 13 jul.2020.

BRASIL. Tribunal de Justiça de São Paulo. Apelação cível n. 1069964-30.2018.8.26.0100. Relator Juiz Henrique Rodrigues Clavisio. São Paulo, 10 mai. 2020. Disponível em https://esaj.tjsp.jus.br/cposg/search.do?conversationld=\&paginaConsulta=0\&cbPesquisa=NUMPROC \&numeroDigitoAnoUnificado $=1069964-$

$30.2018 \&$ foroNumeroUnificado $=0100 \&$ dePesquisaNuUnificado $=106996430.2018 .8 .26 .0100 \&$ dePesq uisaNuUnificado=UNIFICADO\&dePesquisa=\&tipoNuProcesso=UNIFICADO\#. Acesso em: 13 jul. 2020.

BRASIL. Tribunal de Justiça de São Paulo. Apelação Cível n.1007824.78.2015.8.26.0127. Relator Spoladore Dominguez. São Paulo, 15 set. 2016. Disponível em:

https://esaj.tjsp.jus.br/cposg/search.do?conversationld=\&paginaConsulta=0\&cbPesquisa=NUMPROC \&numeroDigitoAnoUnificado $=1007824$ -

78.2015\&foroNumeroUnificado $=0127 \&$ dePesquisaNuUnificado $=1007824-$

78.2015.8.26.0127\&dePesquisaNuUnificado=UNIFICADO\&dePesquisa=\&tipoNuProcesso=UNIFICADO . Acesso em: 13 jul. 2020.

BRASIL. Tribunal de Justiça do Distrito Federal. Recurso inominado no Juizado Especial $\mathrm{n}$. 20040510087275. Relator: Juiz João Batista Teixeira. Distrito Federal, 11 mai. 2005. Disponível em: https://tj-df.jusbrasil.com.br/jurisprudencia/2923846/apelacao-civel-no-juizado-especial-acj20040510087275-df/inteiro-teor-101179045?ref=juris-tabs. Acesso em: 14 jul. 2020.

Brasil. Tribunal de Justiça do Paraná. Apelação Cível n. 13217451. 17a Câmara Cível. Relator: Fernando Paulino da Silva Wolff Filho. Curitiba, 20 out. 2015. Disponível em: https://tjpr.jusbrasil.com.br/jurisprudencia/245171204/apelacao-apl-13217451-pr-1321745-1acordao?ref=serp. Acesso em: 14. Juljul. 2020. 
BRASIL. Tribunal Regional Federal (2a Região). 3a Vara Cível. Ação de Reintegração de Posse n. 0012600-97.2017.4.02.5001 (2017.50.01.012600-0). Juiz Rodrigo Reiff Botelho. Vitória, 10 mai. 2017 https://eproc.jfes.jus.br/eproc/controlador.php?acao=acessar_documento\&doc $=501576438937387$ $311931605886699 \&$ evento $=501576438937387311931605940714 \& \mathrm{key}=219193 \mathrm{ed} 6665 \mathrm{ac} 6222 \mathrm{e} 160 \mathrm{~d}$ 65d4b4c54d607cfd8804527939a2703e45e3040d8\&hash=be1bd8b1c0c93ea2578c40cb4524dca7. Acesso em 13 jul. 2020.

COSTA, Alexandre Bernardino Costa. ACYPRESTE, Rafael de. Ações de reintegração de posse contra o movimento dos trabalhadores sem teto: dicotomia entre propriedade e direito à moradia. Revista de Direito da Cidade, Rio de Janeiro, vol. 08, n. 04, 2018, p. 1824-1867.

FARIAS, Cristiano Chaves de; ROSENVALD, Nelson. Curso de Direito Civil: direitos reais. 15 ed. Salvador: JusPodivm, 2019.

FERREIRA, Allan Ramalho. O Estado veste o traje da morte: a reintegração de posse e a pandemia. Carta Capital, São Paulo, 09 jul. 2020. Disponível em: https://www.cartacapital.com.br/blogs/brcidades/o-estado-veste-o-traje-da-morte-a-reintegracao-de-posse-e-a-pandemia/. Acesso em: 10 jul. 2020.

GAZETA ON LINE. Disponível em https://www.gazetaonline.com.br/noticias/cidades/2017/05/juizautoriza-permanencia-de-familias-que-ocupam-predio-no-centro-de-vitoria-1014053752.html. Acesso em 27 de janeiro de 2019.

GONÇALVES, Carlos Roberto. Direito civil brasileiro: , v. 5: direito das coisas. 7. ed. São Paulo: Saraiva, 2012. V.5

JUIZ autoriza permanência de famílias que ocupam prédio no Centro de Vitória. Gazeta on line, 10 maio 2017, Vitória. Disponível em https://www.gazetaonline.com.br/noticias/cidades/2017/05/juizautoriza-permanencia-de-familias-que-ocupam-predio-no-centro-de-vitoria-1014053752.html. Acesso em 20 ago. 2021.

MARANHÃO, Juliano Souza de Albuquerque; RODRIGUES, Renê Chiquetti. Recurso a princípios morais necessariamente implica valoração moral na identificação do direito?. In: O Positivismo Jurídico no Século XXI. V. 5. TORRANO, Bruno; OMMATI, José Emílio Medauar (Coordenadores). Rio de Janeiro: Lumen Juris, 2018., p. 327-352.

MELO, Marco Aurélio Bezerra de. Curso de Direito Civil, v. V. 5: direito das coisas. São Paulo: Atlas, 2015.

MOURA, Lucia Seidl de; FERREIRA, Maria Cristina; PAINE, Patricia Ann. Manual de elaboração de Projetos de Pesquisa. Rio de Janeiro: EdUERJ, 1998.

PEREIRA, Pablo. A invasão urbana como prática política. Estado de São Paulo, 06 julho 2014. Disponível em: https://sao-paulo.estadao.com.br/noticias/geral,a-invasao-urbana-como-praticapolitica-imp-,1524328. Acesso em 20 ago 2021.

SOBOTA, Katharina. Não mencione a norma! Tradução Trad. João Maurício Adeodato. Anuário do Mestrado da Faculdade de Direito do Recife - UFPE, Recife, n. 7, p. 251-273, 1996. Recife: ed. UFPE, 1996, p. 251-273.

TARTUCE, Flávio. Direito Civil, v. 4: direito das coisas. São Paulo: Método, 2015. V. 4: 
WARAT, Luís Alberto. Saber crítico e senso comum teórico dos juristas. Sequência: Estudos Jurídicos e Políticos, Florianópolis, v. 03, n. o 05, p.45-60, 1982.

Trabalho enviado em 20 de julho de 2020

Aceito em 23 de agosto de 2021 